\title{
Dampak Pernikahan Dini Pada Kesehatan Reproduksi Dan Mental Perempuan (Studi Kasus Di Kecamatan Ilir Talo Kabupaten Seluma Provinsi Bengkulu)
}

\author{
Lezi Yovita Sari, Desi Aulia Umami, Darmawansyah \\ Universitas Dehasen Bengkulu Jalan Merapi Raya Seraya No.43 Kebun Tebeng Bengkulu, 21977 \\ Email: Leziyovitas@gmail.com \\ Desiumami@gmail.com \\ darmawansyah467@yahoo.com
}

\begin{abstract}
ABSTRAK
Pernikahan dini merupakan suatu pernikakan yang dilakukan oleh seseorang yang relatif muda. Umur yang relatif muda yang dimaksud adalah usia pubertas yaitu usia antara 1019 tahun. Suatu daerah di Indonesia salah satunya Kecamatan Ilir Talo Kabupaten Seluma Provinsi Bengkulu, banyak terjadi pernikahan dini. masyarakat pribumi di sana masih menganut suatu budaya yang sebenarnya secara tidak sadar dapat meningkatkan angka pernikahan dini yang berakibat pada dampak kesehatan fisik dan mental. Budaya tersebut adalah budaya selarian, budaya selarian adalah fenomena pernikahan paksa yang dilakukan oleh laki-laki untuk menculik perempuan supaya bisa dinikahinya dengan tanpa meminta restu dari orang tua perempuan. Adapun tujuan penelitian ini di lakukan untuk menggali informasi tentang kejadian dampak pernikahan dini pada kesehatan reproduksi dan mental perempuan di Wilaya Kecamatan Ilir Talo Kabuaten Seluma Provinsi Bengkulu. Penelitian ini menggunakan pendekatan kualitatif studi fenomenologi, pengumpulan data penelitian ini menggunakan, observasi (pengamatan), wawancara mendalam, focus group discussion (FGD), studi dokumentasi. Subyek penelitian sebanyak 17 orang yang melakukan pernikahan dini, dan obyek penelitiannya adalah dampak yang ditimbulkan pernikahan dini. Hasil penelitian ini menunjukan bahwa penyebab kejadian pernikahan di Kecamatan Ilir Talo Kabupaten Seluma Provinsi Bengkulu yaitu hami di luar nikah, seks pranikah, kemauan sendiri, ekonomi, teman sebaya dan budaya selarian yang berkembang di wilaya tersebut, dampak yang di timbulkan terjadinya Anemia, panggul sempit, BBLR, Hipertensi, dan dampak lain yang di timbulkan tejadinya kekerasan dalam rumah tangga (KDRT). Berdasarkan penelitian dapat di simpulkan bahwa kejadian pernikahan dini berdampak pada kesehatan reprosuksi perempuan.
\end{abstract}

Kata Kunci : Pernikahan Dini. Dampak, dan Budaya Selarian

\section{ABSTRACT}

Early marriage is a marriage carried out by someone who is relatively young. The relatively young age that is meant is the age of puberty which is the age between 10-19 years. one indonesia region, one of districts of ilir talo, seluma regency Bengkulu province, Aas many early marriage. The indigenous community there still adheres to a culture that is actually unconsciously able to increase the rate of early marriage which results in the impact of physical and mental health. This culture is a culture of celibacy, The culture of celariation is a phenomenon of forced marriage committed by men to kidnap women, that they can marry without asking for the blessing of their parents. The purpose of this study wa to explore information about the Early movement and mentality of women (case study in region District Ilir Talo subdistrict Seluma Bengkulu Province. This study uses observations of in - depth interviews, study documentation of research subjects as many as 17 people who do early marriage and the object of research is the impact of early marriage.The results of this study indicate that case couses of marital events of marriage events are ilir talo district kabupaten

http://ejournal.urindo.ac.id/index.php/kesehatan

Article History :

Sumbitted 26 Februari 2020, Accepted 29 Juni 2020, Published 30 Juni 2020 
seluma Bengkulu province, namely pregnancy, outside marriage, premarital sex, self - will, peer econo mics, and a culture that develops throughout the region. The impact of anemia, , othwr effects caused by low birth weight occurrence of domestic violence. Based on the research it can be concluded that the events at the beginning of the party on women's reproductive health.

Keywords: Early marriage. Impact and Culture Selarians

\section{PENDAHULUAN}

Pernikahan adalah ikatan batin antara pria dan wanita sebagai suami istri dengan tujuan membentuk keluarga/ rumah tangga yang bahagia dan kekal berdasar Ketuhanan Yang Maha Esa (UU Perkawinan No 1 Tahun 1974). Dalam UU No. 1 tahun 1974, pasal 7 ayat (1) menyatakan bahwa perkawinan hanya diijinkan bila laki- laki berumur 19 tahun dan wanita berumur 16 tahun, usulan perubahan pada pasal 7 tahun 1974 ayat (1) perkawinan dapat dan dilakukan jika pihak laki-laki dan perempuan berusia minimal 19 tahun, pasal 6 ayat (2) untuk melangsungkan pernikahan masing-masing calon mempelai yang belum mencapai umur 21 tahun, harus mendapat izin kedua orang tua. ${ }^{(1)}$

Dalam 30 tahun terakhir, perkawinan usia anak di seluruh dunia telah mengalami penurunan dari 33\% pada tahun 1985 menjadi 26\% pada tahun 2010. Lebih dari 700 juta perempuan yang hidup saat ini menikah sebelum mencapai usia 18 tahun, dan sepertiga atau sekitar 250 juta anak menikah sebelum usia 15 tahun. Diperkirahkan 142 juta anak perempuan (atau 14,2 juta pertahun) akan menikah sebelum usia 18 tahun dari tahun 2011 sampai 2020. Perkawinan usia anak paling umum dipraktikkan di Asia Selatan dan Afrika Sub-Sahara. India, yang memiliki prevalensi perkawinan usia anak sebesar $58 \%$, atau lebih dari sepertiga jumlah perkawinan usia anak di seluruh dunia. Dari 10 negara dengan prevalensi perkawinan usia anak tertinggi, 6 negara diantaranyaberada di Afrika, termasuk Nigeria, yang memiliki prevalensi tertinggi yaitu $77 \%{ }^{(2)}$

Badan Pusat Statestik dan UNICEF mencatat indikasi pernikahan anak terjadi di hampir semua wilayah ndonesia. Ratarata prevalensi perkawinan usia anak (perempuan 20-24 tahun yang perna menikah sebelum umur 18 tahun) 20082012 tertinggi adalah Sulawesi Barat $(37,0)$, Kalimantan tengah $(36,3)$, Sulawesi Tengah $(34,9)$, Papua $(33,6)$, sedangkan Provinsi Bengkulu menempati posisi ke 19 dari 33 provinsi yang ada di Indonesia. Jumlah remaja yang perna kawin pada tahun 2012 sebanyak 7.424 wanita, sedangkan prevalensi pernikahan usia dini sebesar 10,2. ${ }^{(3)}$

Kabupaten Seluma provinsi Bengkulu terdiri dari 14 kecamatan yang salah 
satunya adalah kecamatan Ilir Talo. Di kecamatan llir Talo yang terdiri dari 15 Desa tercatat masih tinggi angka pernikahan dini dan terjadi peningkatan yang signifikan dari tahun 2013- 2016 yaitu dari 654 pasangan pernikahan terdapat 218 (33,3\%) kejadian pernikahan dini dengan usia 16-19 tahun dan pada tahun 2017 dari 139 pasangan pernikahan terdapat 50 (43.3\%) kejadian pernikahan dini dengan usia 16-19 tahun.

Masih tingginya angka pernikahan dini, sudah tentu banyak sekali permasalahan yang dihadapi oleh wanita yang melakukan pernikahan tersebut, yang mengakibatkan dampak yang sangat merugikan pihak perempuan, baik dari segi fisik, psikis, ekonomi, otonomi dan pendidikan Sehubungan dengan hal tersebut, peneliti tertarik untuk melakukan penelitian. Tujuan umum penelitian ini dilakukan untuk menggali informasi tentang kejadian dampak pernikahan dini pada kesehatan reproduksi dan mental perempuan (studi kasus) di Kecamatan Ilir Talo Kabupaten Seluma Provinsi Bengkulu Tahun 2018.

\section{METODE PENELITIN}

Penelitian ini merupakan penelitian survey dengan pendekatan kualitatif studi fenomenologi, digunakan untuk mempelajari secara mendalam kasus pernikahan dini di Kecamatan Ilir Talo Kabupaten Seluma, meliputi penyebab serta dampak yang ditimbulkannya. Subyek Penelitian Seluruh Perempuan yang melakukan pernikahan dini di Kecamtan Ilir Talo Tahun 2017 sebanyak 17 orang. Obyek penelitian adalah penyebab dan dampak yang di timbulkan oleh pernikahan dini pada perempuan di Kecamatan Ilir Talo Tahun 2017. Pengumpulan Data kualitatif menggunakan observasi, wawancara mendalam, studi dokumentasi dan FGD ( focus group discussion). Teknik Analisis Data ini adalah proses mengidentifikasi mengkategori mengambi kesimpulan berdasarakan informasi yang diperileh melalui pedoman observasi, pedoman wawancara, studi dokumentasi dan FGD ( focus group discussion). Analisis data dalam penelitian ini menggunakan analisis isi (content analys).

\section{HASIL PENELITIAN}

Hasil Analisis Data Kualitatif

Variabel yang di analisis
menggunaka data kualitatif dalam
penelitian ini adalah variabel penyebab
dan dampak pernikahan dini dan vaiabel
budaya selarian.


Tabel 1. Karakteristik Informan Penelitian

\begin{tabular}{cclll}
\hline No & Nama & \multicolumn{1}{c}{ Umur } & \multicolumn{1}{c}{ Pendidikan } & \multicolumn{1}{c}{ Keterangan } \\
\hline 1 & X1 & 16 Tahun & SD / (3 SLTP) & MBA (Marriged By Acident) \\
2 & X2 & 18 Tahun & SMA & MBA (Marriged By Acident) \\
3 & X3 & 16 Tahun & SMP (1 SMA) & MBA (Marriged By Acident) \\
4 & X4 & 16 Tahun & SD (3 SLTP) & Kawin Lari ( Selarian) \\
5 & X5 & 17 Tahun & SMP (3 SMA) & MBA (Marriged By Acident) \\
6 & X6 & 16 Tahun & SD ( 3 SMP) & MBA (Marriged By Acident) \\
7 & X7 & 18 Tahun & SMA & MBA (Marriged By Acident) \\
8 & X8 & 15 Tahun & SD (3 SMP) & Seks Pranikah \\
9 & X9 & 15 Tahun & SMP & Kemauan Sendiri \\
10 & X10 & 16 Tahun & SMP (1 SMA) & MBA (Marriged By Acident) \\
11 & X11 & 17 Tahun & SMP ( 2 SMA) & Seks Pranikah \\
12 & X12 & 16 tahun & SMP ( 1 SMP) & Seks Pranikah \\
13 & X13 & 17 Tahun & SMP & MBA (Marriged By Acident) \\
14 & X14 & 16 Tahun & SD (3 SMP) & MBA (Marriged By Acident)/ Selarian \\
15 & X15 & 17 Tahun & SD (3 SMP) & Seks Pranikah / Selarian \\
16 & X16 & 16 Tahun & SD (3 SMP) & Seks Pranikah / selarian \\
17 & X17 & 15 Tahun & SD (3 SMP) & Seks Pranikah / Selarian \\
\hline
\end{tabular}

Tabel 2. Distribusi frekuesi Umur informan

\begin{tabular}{llcc}
\hline No & Umur & N & $\%$ \\
\hline 1 & 15 tahun & 3 & $17,6 \%$ \\
2 & 16 tahun & 8 & $47,1 \%$ \\
3 & 17 tahun & 4 & $23,5 \%$ \\
4 & 18 tahun & 2 & $11,7 \%$ \\
& Jumlah & 17 & 100,00 \\
\hline
\end{tabular}

Tabel 2. bahwa informan yang menikah pada umur 15 tahun sebanyak 3 informan $(17,6 \%)$ sedangkan yang menikah pada umur 16 tahun sebanyak 8 informan
$(47,1 \%)$ serta yang menikah pada umur 17 tahun sebanyak 4 informan $(23,5 \%)$ dan yang menikah pada umur 18 tahun sebanyak 2 informan (11,7\%).

Tabel 3. Distribusi frekuesi pendidikan informan

\begin{tabular}{|c|c|c|c|}
\hline No & Pendidikan & $\mathrm{N}$ & $\%$ \\
\hline 1 & SD & 8 & 53,3 \\
\hline 2 & SMP & 7 & 46,7 \\
\hline 3 & SMA & 2 & 13,3 \\
\hline & Jumlah & 17 & 100,00 \\
\hline
\end{tabular}

Tabel 3. diatas bahwa bahwa informan yang melakukan pernikahan dini dengan pendidikan SD sebanyak 8 informan $(53,3)$ sedangkan yang berpendidikan SMP sebanyak 7 informan $(46,7)$ dan yang berpindidikan SMA sebanyak 2 informan (13,3\%). 
Penyebab Pernikahan Dini (Marriged By Acident)

Pada penelitian ini banyak sekali informan yang menikah karena hamil diluar nikah, hal ini terjadi karena informan sangat rentan terhadap perilaku seksual yang membuat informan melakukan aktivitas seksual sebelum menikah, hal ini terjadi karena adanya kebebasa pergaulan pada informan. sehingga terjadi pernikahan dini yang disebabkan (Marriged By Acident). Pada penelitian ini ada informan yang menikah dengan dengan cara kawin lari (selarian) merupakan adat di daerah tersebut, hal ini dilakukan untuk mempercepat mendapatkan restu kepada orang tua dan mempercepat pada proses pernikahan. Sebanyak 17 informan 9 informan yang mengalami hamil sebelum menikah 1 diantaranta menikah dengan proses kawin lari (selarian).

Pada penelitian ini banyak informan yang menikah karena sudah melakukan seks pranikah atau seksual sebelum menikah. Bermacam-macam bentukbentuk perilaku seks pranikah yang dilakukan oleh informan yaitu: Kissing (berciuman), Petting, Intercourse (bersenggama). Dapat diketahui juga ada beberapa faktor yang mempengaruhi informan melakukan hubungan seks pranikah di usia remaja yaitu: peran orang tua dalam mendidik anak, kelompok bermain, media massa, usia yang erat hubungannya dengan kematangan seks (masa puberitas), pengalaman hubungan afeksi (pacaran), mudahnya mengakses hal-hal terkait seksualitas, dan juga disebabkan karena sudah semakin bebasnya pergaulan para remaja di lingkungan masyarakat sehingga memarakkan munculnya fenomena tentang perilaku seks pranikah dikalangan remaja, yang diiringi semakin lemahnya kekuatan norma-norma yang berlaku pada masyarakat dalam mengkondisikan bagian masyarakat itu sendiri. Pada penelitian ini ada informan yang menikah dengan dengan cara kawin lari (selarian) merupakan adat di daerah tersebut, hal ini dilakukan untuk mempercepat mendapatkan restu kepada orang tua dan mempercepat pada proses pernikahan. Dari 17 informan 7 diantaranya menikah karena sudah melakukan seks pranikah 4 diantaranya menikah dengan proses kawin lari (selarian).

Kemauan sendiri

Faktor ekonomi salah satu penyebab terjadinya pernikahan dini karena minimnya pendapatan orang tua yang mengakibatkan informan tidak bisa melanjutkan pendidikan dan memilih untuk menikah diusia yang masih sangat remaja. Sedangkan pendidikan adalah salah satu faktor yang bisa mempengaruhi pengetahuan dan pengambilan keputusan, 


\section{Jurnal Bidang IImu Kesehatan}

dengan melanjutkan pendidikan informan

akan lebih mudah dalam mendaptkan ilmu

pengetahuan yang luas. Namun

keadaanlah yang mengharuskan informan untuk menikah dengan tujuan untuk tidak membebani orang tua. Dari 17 informan diatas 1 diantaranya menikah dengan kemauan sendiri.

\section{Dampak Pernikahan Dini Dampak Biologis}

Tabel 4. Dampak Biologis yang ditimbulkan akibat pernikahan dini

\begin{tabular}{llll}
\hline No & & Dampak Biologis & N \\
\hline 1 & BBLR & 3 \\
2 & Anemia & 4 \\
3 & Hipertensi & 1 \\
& Jumlah & 8 \\
\hline
\end{tabular}

Tabel 4. diatas didapatkan dari 17 informan 3 informan yang mengalami BBLR, 4 informan mengalami Anemia dan 1 informan yang mengalami hipertensi.

\section{Dampak Psikologis}

Dampak Psikologis pernikahan dini pada penelitian ini juga menimbulkan penyesalan dalam diri informan, dari 17 informan 2 diantaranya mengalami KDRT, seringnya pertengkaran dan percekcokan dalam rumah tangganya membuat informan menjadi takut dalam menjalani rumah tangganya ke depan karena terjadinya kekerasan dalam rumah tangga (KDRT).

\section{PEMBAHASAN}

\section{Pernikahan Dini}

Berdasarkan hasil penelitian diatas, dari tujuh belas responden yang menjadi objek penelitian. Menikah pada usia masih sangat muda pasti banyak memiliki kekurang seperti belum adanya kematangan yang di miliki. Dari 17 kasus pernikahan dibawah umur diatas dapat diketahui bahwa faktor-faktor terjadinya pernikahan di sebabkan oleh berbagai macam permasahan, ada yang menikah karena kemauan sendiri, ada juga karena permasalahan ekonomi orang tua dan ada juga karena kehamilan di luar nikah. Serta ada pula yang karena sudah melakukan seks pranikah dan kemauan sendiri.

\section{Peran Orang Tua}

Kurangnya komunikasi secara terbuka antara orang tua dengan remaja dalam masalah kesehatan reproduksi, sehingga munculnya penyimpangan prilaku seksual. Orang tua sangat dibutuhkan bagi tumbuh kembang anak di segala aspek, perkembangan fisik, intelektual, emosi, moral, kepribadian dan spiritual. Kebutuhan akan kelekatan psikologis, kebutuhan akan stimulasi fisik dan mental 


\section{Jurnal Bidang Ilmu Kesehatan}

dimana diperlukan perhatian yang sangat besar dari orang tuanya, serta kebutuhan rasa aman merupakan kebutuhan dasar yang harus dipenuhi bagi anak agar dapat mencapai tumbuh kembang optimal.

\section{Faktor Umur}

Berdasarkan dari penelitian diatas, dari 17 responden yang menjadi objek penelitian rata-rata menikah pada umur 15-19 tahun. Dari 17 kejadian pernikahan dini di atas dapat di ketahui nahwa penyebab terjadinya pernikahan di sebebkan berbagai macam permasalahan, ada yang hamil sebelum menika, seks pranikah, kemauan sendiri, dan selarian (kawin lari).

\section{Faktor Ekonomi}

Berdasarkan dari penelitian diatas, dari 17 responden yang menjadi objek penelitian rata-rata menikah pada umur 15-19 tahun. Dari 17 kejadian pernikahan dini di atas dapat di ketahui nahwa penyebab terjadinya pernikahan di sebebkan berbagai macam permasalahan, ada yang hamil sebelum menika, seks pranikah, kemauan sendiri, dan selarian (kawin lari). Hasil penelitian ini Sejalan dengan penelitian yang dilakukan Zuraidah dari hasil penelitiannya didapatkan nilai $p=$ 0,000 , yang artinya ada hubungan yang signifikan antara status ekonomi dengan pernikahan dini pada wanita. ${ }^{(4)}$

\section{Faktor Pendidikan}

Berdasarkan hasil di atas rata-rata informan menikah hanya tamatan SD dan
SMP, kurangnnya pengetahuan tentang dampak pernikahan dini terhadap kesehatan reproduksi yang membuat remaja ingin menikah, semakin rendahnya tingkat pendidikan seseorang semakin besar peluang mereka untuk melakukan pernikahan dini namun sebaliknya jika seseorang tersebut berpendidikan tinggi cenderung mereka tidak melakukan pernikahan dini, Penelitian Ini sejalan dengan penelitian yang di lakukan (Srihartini, hubungan antara variabel tingkat pendidikan wanita $(X)$ dan usia perkawinan (Y) adalah linier. Artinya semakin tinggi pendidikan seseorang, maka akan semakin lama seseorang menunda perkawinan atau sampai mencapai usia ideal. Semakin rendah tingkat pendidikan seseorang, maka semakin cepat seseorang akan melangsungkan perkawinan, khususnya masyarakat di Desa Sidomukti Kecamatan Jaken Kabupaten Pati. ${ }^{(5)}$

\section{Faktor Kemauan Sendiri}

pernikahan adalah sesuatu yang
diimpikan oleh setiap orang tetapi
pernikahan juga harus memiliki kesiapan baik dalam psikologis maupun biologis di Kecamatan Ilir Talo Kabupaten Seluma masih banyak yang melakukan pernikan dini dengan alasan yang berbeda-beda sala satunya keinginan sendiri dengan tujuan untuk tidak membebani orang tua lagi, salah satu masalah mengapa informa memilih untuk menikah di usia dini karna minimnya ekonomi orang tua sehinggaga 
tidak bisa melanjutkan ke jenjang pendidikan yang lebih tinggi, informan beranggapan banyak teman-temannya yang menikah di usia dini dan mereka hidup bahagai sehingga informan memutuskan untuk menikah di usia yang masih sangat mudah. Penelitian ini sajalan dengan hasil studi literasi UNICEF yang menemukan bahwa interaksi berbagai faktor menyebabkan anak berisiko menghadapi pernikahan di usia dini. Sehingga secara luas dapat diketahui bahwa pernikahan anak berkaitan dengan tradisi dan budaya, sehingga sulit untuk mengubahnya. ${ }^{(2)}$

\section{Faktor Teman sebaya}

Pernikahan Dini yang terjadi salah satunya pengaru besar yang di pengaruhi dari teman sebaya karena pada remaja saat ini mereka sudah mengerti mengenai seks pranikah. Apabilah seseorang sudah melakukan seks pranikah maka dia akan menceritakan pengalamannya itu dengan teman dekatnya. Berdasarkan cerita dari temannya tersebut maka muncullah rasa penasaran ingin melakukan seks pranikah juga dengan pacarnya, sehingga informasi tersebut menyebar dengan teman-teman yang lain, yang mana mereka bisa secara bebas melakukan seks pranikah tanpa sepengetahuan orang tuanya, rasa penasaran itu tidak hanya terjadi pada seks pranikah saja, tetapi rasa penasaran itu juga muncul pada saat melihat temannya menikah. berdasarkan rasa ingin tahu tersebut seseorang akan melakukan hal yang sama yaitu menikah pada usia dini. dalam hal ini peran orang tua sangat penting dalam mengawasi anaknya agar anaknya tidak melakukan pergaulan bebas, yang mana apabilah sudah terjadi pergaulan bebas dapat terjadi kehamilan diuar nikah. Penelitian ini sejalan dengan penelitian yang di lakukan Eka Khaparistia, menunjukkan bahwa faktor yang mempengaruhi pernikahan dini adalah faktor ekonomi, teman sebaya, keinginan dari informan, keluarga, dan hamil di luar nikah. ${ }^{(6)}$

\section{Faktor Media Massa}

Berdasarkan hasil penelitian pernikahan dini yang tejadi salah satunya pengaru dari media massa yang mana remaja secara bebas menonton video porno, majalah-majala porno sehingga membuat ketertarikan kepada remaja untuk mencoba hal-hal yang telah dilihat. Tanpah mengetahui dampak apa yang akan terjadi, Penelitian ini sejalan dengan Nazli Halawani Pohan, Ada hubungan antara media massa dengan pernikahan usia dini pada remaja putri dengan nilai $p=0,045$ yang berarti lebih kecil dari $\alpha=0,05$, serta nilai Odd Ratio (OR) sebesar 2,25 yang berarti bahwa remaja putri yang terpapar media massa mempunyai resiko 2,25 kali menikah dini dibanding remaja puri yang tidak terpapar media massa. ${ }^{(7)}$ 


\section{Faktor MBA ( Marriged By Acident )}

Pasangan yang menikah di usia dini sesusnggunya mereka belum mempunyai pola piker yang luas, pengaru lingkungan adalah hal yang kuat terjadinya penikahan dini karena setiap remaja sudah mengenal yang namanya pacaran sehingga remaja berpikir kalau mereka tidak mempunyai pacar mereka merasa orang yang kurang beruntung atau kurang cantik, hal ini yang menjadi pendorong mereka untuk memulai berpacaran sehingga terjadila cinta kasih. Awalnya mereka hanya ingin tau setelah tau mereka mencoba-coba setelah mencoba mereka menikmati sehingga terjadilah kehamilan di luar nikah yang mengakibatkan remaja harus menikah. Tidak mengerti akibat dari pernikahan dini yang disebabkan belum begitu matang untuk berpikir seperti apa dampaknya setelah menikah. Penelitian ini sejalan dengan penelitian Puji Hastuti, Bahwa Kehamilan terjadi akibat melakukan hubungan seks sebelum menikah dengan pacarnya, karena permintaan pacar dan rangsangan dari tontonan pornografi. ${ }^{(8)}$

\section{Faktor Seks Pranikah}

Sebagian besar informan melakukan pernikahan dini karena sudah melakukan seks pranikah, Semakin banyak remaja mendengar, melihat dan mengalami hubungan seksual maka semakin kuat stimulasi yang mendorong munculnya prilaku seksual tersebut, misalnya melihat gambar - gambar porno diinternet ataupun mendengar obrolan dari teman mengenai pengalaman seksual. Penelitian ini didukung oleh hasil penelitian Stang dan Etha Mambaya dalam Kanella Ayu Wulanuari, yang menyatakan ada hubungan dari seks pranikah dengan pernikahan usia dini yang kemudian berujung pada kehamilan yang tidak diinginkan. ${ }^{(9)}$

\section{Faktor Budaya Selarian}

Berdasarkan hasil penelitian di atas, sebagian besar informan menikah dengan "selarian" atau dalam bahasa talo menyubutnya kawin lari, suatu adat yang diperbolehkan dalam masyarakat, akan tetapi selarian dapat menimbulkan dampak negative dalam suatu perkawinan, penyebab mereka melakukan selarian sangat beragam ada yang di sebabkan $M B A$ ( Marrid by accident) ada yang sudah melakukan seks pranikah dan ada juga yang karena kemauna sendiri. Hal tersebut sejalan dengan penelitian yang dilakukan oleh Djamilah, Reni Kartikawati, Dampak Perkawinan Anak di Indonesia Jurnal Studi Pemuda pada tahun 2014, jumlah kasus perkawinan siri bawah umur di Lombok yang tidak dicatatkan cukup tinggi. Salah satu faktor tingginya angka perkawinan siri tersebut dikarenakan adanya budaya "Merariq" atau kawin lari yang dianut oleh Masyarakat asli Lombok, yaitu Suku Sasak. Selain itu, di Lombok juga memiliki istilah "Mosot", yaitu sebutan bagi remaja baik 
perempuan atau laki-laki yang belum menikah di umur $<17$ thn. ${ }^{(10)}$

\section{Dampak Pernikahan Dini}

\section{Dampak Biologis}

Berdarakan hasil penelitian di atas didapat bahwa dampak biologis yang di timbulkan saat hamil dan melahirkan terjadinya BBLR, Anemia dan Hipertensi, hal tersebut terjadi karena fungsi reproduksi yang belum siap untuk hamil dan melahirkan. Secara biologis alat reproduksi wanita masih dalam proses menuju kematanga sehingga belum siap untuk menghadapi walapun fisik dalam keadaan sehat, hal tersebutlah yang tidak diketahui oleh remaja-remaja yang melakukan pernikahan diusia dini sedangkan hal tersebut sangat membahayakan bagi ibu dan bayi. Untuk resiko kebidanan, hamil dibawah usia 19 tahun beresiko pada kematian, terjadinya perdarahan, keguguran, hamil anggur dan hamil prematur. Sementara kualitas anak yang dihasilkannya: Bayi Berat Lahir Rendah (BBLR) sangat tinggi, Risiko melahirkan anak cacat, Memiliki kemungkinan 5- 30 kali besar risiko bayi meninggal. (11)

\section{Dampak Psikologi}

Berdarakan hasil penelitian didapat bahwa sebagian besar informan mengatakn bahwa mereka merasakan tidak mempunyai kebebasan dan timbulnya rasa peneyesalan setelah menikah. seringnya terjadi pertengkaran dan percekcokan dalam rumah tangganya membuat informan menjadi takut dalam menjalani rumah tangganya ke depan karena selalu terjadi kekerasan dalam rumah tangga (KDRT). Terjadinya pernikahan dini membuat remaja tidak bisa melanjutkan sekolahnya ke jenjang yang lebih tinggi sehingga tidak tercapai cita-cita yang mereka inginkan. mereka sangat menyesal karena sekolah hanya sampai SD dan SMP dan tidak bisa melanjutkan sekolah lagi karena mereka sudah mempunyai anak sehingga Informan harus merawat anaknya. Hal tersebut sejalan dengan penelitian yang dilakukan oleh Stefania dan Kawan kawan tentang Hubungan Antara Usia Waktu Menikah Dengan Kejadian Kekerasan Dalam Rumah Tangga di Manado, bahwa banyak kasus KDRT terjadi pada usia waktu menikah dini di bandingkan dengan usia waktu menikah dewasa. ${ }^{(12)}$

\section{Dampak Positif}

Berdasarkan hasil penelitian diatas, sebagian kecil informan mengatakan setelah menikah mempunyai tanggung jawab baru sebagai seorang istri dan selalu mendapatkan dukunngan-dukungan emosional dan spiritual dari pasangan. Menurut Kumalasari, pernikahan dini tidak hanya memberikan dampak yang buruk atau negatif, masih ada segi postif yang dapat dicermati dari pernikahan tersebut, diantaranya adalah : Akan terhindar dari prilaku sex bebas, Ketika menginjak usia 
tua sudah tidak lagi mempunyai anak yang masih kecil, Terpenuhinya segala kebutuhaan, seperti kebutuhan biologis, psikologis, sosial dan ekonomi. Penelitian ini sejalan dengan penelitian yang dilakukan Beteq Sardi 2016 bahwa dampak postip pernikahan dini dapat membantu meringankan beban ekonomi orang tua, dan mencegah terjadinya perzinaan dikalangan remaja, dan dapat memberikan pengajaran pada anak untuk mempunyai rasa tanggung jawab dan belajar untuk memenuhi kebutuhan hidup sehari-hari. ${ }^{(13)}$ (14)

\section{Dampak Lingkungan Sosial (selarian)}

Berdasarkan hasil penelitian diatas, rata-rata informan menikah dengan cara selarian (kawin lari) penyebab mereka melakukan selarian sengat beragam ada yang hamil di luar nikah, ada yang sudah melakukan seks pranikah, sehingga selarian adalah jalan satu-satunya untuk mendapatkan restu. kawin lari sudah menjadi budaya yang sudah di percaya dari sejak dulu hingga sekarang. Hal ini sejalan dengan penelitian yang dilakukan oleh Yunita, yang menyatakan bahwa ada hubungan antara sosial budaya dengan pernikahan usia dini pada remaja. Budayabudaya tersebut dipercayai oleh remaja putri karena kurangnya pengetahuan remaja putri tentang kesehatan reproduksi. (15)

\section{SIMPULAN}

Berdasarkan hasil penelitian yang telah dipaprkan pada bab-bab sebelumnya dapat diambil kesimpulan bahwa :

1. Angka pernikahan dini yang tinggi di Kecamtan Ilir Talo Kabupaten Seluma di sebabkan oleh hamil di luar nikah (Marriged by accident), seks pranikah, teman sebaya, peran orang tua, kemauan sendiri, dan budaya.

2. Dampak yang ditimbukan dari pernikhan dini adalah kurangnya pengetahuan terhadap kesehatan reproduksi sehingga terjadinya anemi, BBLR dan Hipertensi. Serta dampak lain yang ditimbulkan dari pernikahan dini terjadinya kekerasan dalam rumah tangga (KDRT) yang di akibatkan karena ekonomi, kurangnya komunikasi yang bisa berujung dengan perceraian, serta tidak dapat melanjutkan pendidikan, tidak tercapai cita-cita yang diinginkan dan merasa tidak ada kebebasan lagi untuk berkumpul dan bermain dengan teman-teman sebaya.

3. Budaya selarian sudah turun temurun menjadi tradisi dari zaman dahulu dan masih di anut sampai sekarang .

4. Penanganan kasus pernikahan dini di kecamatan ilir talo kabupaten seluma tim kesehatan mengajak untuk lintas sector bersama-sama untuk menurunkan angka pernikahan dini, dengan cara penyuluhan ke sekolahsekolah menenga pertama dan sekolah 
menenga atas yang sebelumnnya hanya dilakukan satu tahun sekali sekarang harus ditambah supaya bisa mewujudkan remaja-remaja yang berkualitas, dari BKKBN sekarang sudah ada program BKR ( Bina Keluarga Remaja), dalam hal tersebut bukan hanya remaja saja yang dibina tetapi orangtuanya juga.

\section{DAFTAR PUSTAKA}

UUD R.I. Undang- Undang Republik Indonesia Nomor 1 Tahun 1974 Tentang Perkawinan. http://hukum.unsrat.ac.id. 1974.

Unicef. Kemajuan yang Tertunda: Analisis Data Perkawinan Usia Anak Di Indonesia. Badan Pusat Statistik, Jakarta Indonesia. 2015.

BPS Provinsi Bengkulu. Badan Pusat Statistik Provinsi Bengkulu 2015. BPS Provinsi Bengkulu. 2016.

Zuraidah. Analisis Pencapaian Pendewasaan Usia Perkawinan di Kecamatan Pancurbatu Kabupaten Deli Serdang tahun 2015. Jurnal Penelitian Kesehatan Suara Forikes: Volume VII Nomor 1, Januari 2016 ISSN: 2086-3098. 2016.

Sri hartini. Psikologi Pendidikan. Surakarta:BP-FKIP UMS. 2014.

Eka Khaparistia,dkk. Faktor-Faktor Penyebab Terjadinya Pernikahan
Usia Muda Studi Kasus di Kelurahan Sawit Seberang Kecamatan Sawit Seberang Kabupaten Langkat. Universitas Sumatera Utara. Medan. 2015.

Pohan, Nazli Halawani. Faktor Yang Berhubungan Dengan Pernikahan Usia Dini Terhadap Remaja Putri. Jurnal Endurance 2(3) October 2017.

Puji Hastuti. Gambaran Terjadinya Pernikahan Dini Akibat Pergaulan Bebas. Jurnal Riset Kesehatan. Poltekes Kemenkes Semarang. 2016. Wulanuari, Kanella Ayu, Anggi Napida Anggraini, and Suparman Suparman. "Faktor-Faktor yang Berhubungan dengan Pernikahan Dini pada Wanita." Jurnal Ners dan Kebidanan Indonesia $5.1 \quad$ (2017): 68-75.10. Djamilah,

Reni Kartikawati, 2014. Dampak Perkawinan Anak di Indonesia. Jurnal Studi Pemuda. Yogyakarta.

Janiwarty, Bethsaida; Pieter, Herri Zan. Pendidikan Psikologi untuk Bidan Teori dan Terapan. Yogyakarta : Andi Offset. 2013.

Stefania, dkk. Hubungan Antara Usia Waktu Menikah Dengan Kejadian Kekerasan Dalam Rumah Tangga. Manado. 2013.

Kumalasari, Intan dan Iwan Adhyantoro. Kesehatan Reproduksi Untuk 
Jurnal Bidang Ilmu Kesehatan

$\begin{array}{lll}\text { Mahasiswa Kebidanan Dan } & \text { Sosiatri-Sosiologi 4.3 (2016): 194- } \\ \text { Keperawatan. Jakarta: Salemba } & 207 . \\ \text { Medika. 2012. } & \text { Yunita. Penggunaan Permainan Edukatif } \\ \text { Beteq. "faktor-faktor pendorong } & \text { Unruk Mengembangkan Kreativitas } \\ \text { pernikahan dini dan dampaknya di } & \text { Anak Usia Dini dalam Keluarga di } \\ \text { Desa Mahak Baru Kecamatan Sungai } & \text { Desa Grabag. Jurnal. Semarang: } \\ \text { Boh Kabupaten Malinau." Ejournal } & \text { UNNES. 2009. }\end{array}$

